\begin{tabular}{lcccr} 
T H E & A R C H I V E & O F & M E C H A N I C A L & E N G I N E E R I N G \\
\hline VOL. LVIII & 2011 & Number 4
\end{tabular}

10.2478/v10180-011-0025-3

Key words: multibody systems, raytracing, coupled dynamical-optical simulation, multidisciplinary optimization

NICOLAI WENGERT* ${ }^{*}$ PETER EBERHARD *

\title{
OPTIMIZATION OF THE DYNAMICAL BEHAVIOR OF HIGH-PERFORMANCE LENS SYSTEMS TO REDUCE DYNAMIC ABERRATIONS
}

\begin{abstract}
In high-performance optical systems, small disturbances can be sufficient to put the projected image out of focus. Little stochastic excitations, for example, are a huge problem in those extremely precise opto-mechanical systems. To avoid this problem or at least to reduce it, several possibilities are thinkable. One of these possibilities is the modification of the dynamical behavior. In this method the redistribution of masses and stiffnesses is utilized to decrease the aberrations caused by dynamical excitations.

Here, a multidisciplinary optimization process is required for which the basics of coupling dynamical and optical simulation methods will be introduced. The optimization is based on a method for efficiently coupling the two types of simulations. In a concluding example, the rigid body dynamics of a lithography objective is optimized with respect to its dynamical-optical behavior.
\end{abstract}

\section{Introduction}

High-performance objectives, especially lithography objectives, are one of the most precise machines in relation to their dimension. Lithography objectives are used in manufacturing semiconductor devices [1]. In general, their purpose is to provide a good image quality at high resolution. This requires highest accuracies in producing and mounting its components. During the application, disturbances should be kept away to maintain the high image quality. A potential disturbance is dynamical excitation. Regarding a lithography objective in a wafer stepper, this could be vibrations from the ground, noise produced by coolers or by the waver stepper itself, etc.

* Institute of Engineering and Computational Mechanics, University of Stuttgart, Pfaffenwaldring 9, 70569 Stuttgart, Germany;

E-mail: [nicolai.wengert, peter.eberhard]@itm.uni-stuttgart.de 
Despite the heavy frame of the objectives, small excitations can make the lenses vibrate so that the projected image is aberrated, i.e. erroneous.

Making the objectives independent of disturbances is a main task of the mechanical designer. This principally concerns the dynamics of the housing and the lens mountings. Some possibilities for decoupling the image quality from excitations are listed below.

- The motion of the lenses can be passively minimized by stiffening all supports, by means of passive damping or by absorbers. However, there are limitations due to the requirement of allowing for a compensation of thermal expansion.

- Active vibration damping by means of active mounts could be used to suppress residual vibrations.

- Instead of suppressing residual vibrations, lenses could be actively deformed to compensate occurring aberrations by opposite aberrations [2].

- If the lens vibrations cause small aberrations, either less or perhaps no active vibration damping is needed. This issue requires mode shapes with small aberrations in relevant frequency ranges. Mode shapes can be controlled by modifying masses and stiffnesses.

The first two points are typical and well-known dynamical problems, whereas the last two points require combined methods of mechanics and applied optics. In this paper, the last point will be described in detail, including all necessary principles. However, some restrictions have to be made. In the dynamical part deformations will be neglected. The same applies to waveoptical effects like diffraction in the optical part, so only geometrical optics will be discussed.

\section{Evaluating a dynamical-optical system}

Coupling dynamical and optical simulations is a multidisciplinary problem. The computation methods differ completely, except some few numerical methods which occur in both fields. So the definition of interfaces is a determining point. For this kind of coupled simulation, a straight-forward method is the most convenient way. It starts with computing the motion of the lenses. The results are passed in terms of moved and tilted lenses to the optical simulation, i.e. the raytracing simulation. Raytracing means calculating the path of light rays through an optical system. It is used to calculate the aberrations for each simulation step. Since all optical systems produce aberrations even in a non-perturbed state, the aberrations are computed relatively to these reference aberrations.

At first, modeling the mechanical part will be shortly described. This is followed by an overview about calculating the optical aberrations. After this, 
the Zernike polynomials are introduced in order to utilize them for quantifying aberrations. In both the mechanical and the optical part, a Cartesian system is used where the $z$-axis is the axis of rotational symmetry. In the optical model, this is called the optical axis. The positive $z$-direction is the direction of the light, starting at the object plane and ending at the image plane.

\subsection{Modeling rigid lens systems}

For deriving the mechanical model, the design of a lithography objective is used. It consists of a stack of lens holding devices which are subdivided into outer rings, inner rings and lenses. The outer rings are fixed to each other so that they form the housing. The inner rings hold the lenses that are connected to the outer rings by different types of mechanisms for fine position adjustments, see e.g. [3].

The model is built by means of multibody system (MBS) formalisms, see [4]. The holding devices are simplified to groups of rigid bodies which are connected by spring elements. It is assumed that no additional damping is present, and structural damping is neglected due to the small influence on the dynamical-optical behavior. A small lens system with its connection to a fixed environment is shown in Fig. 1.

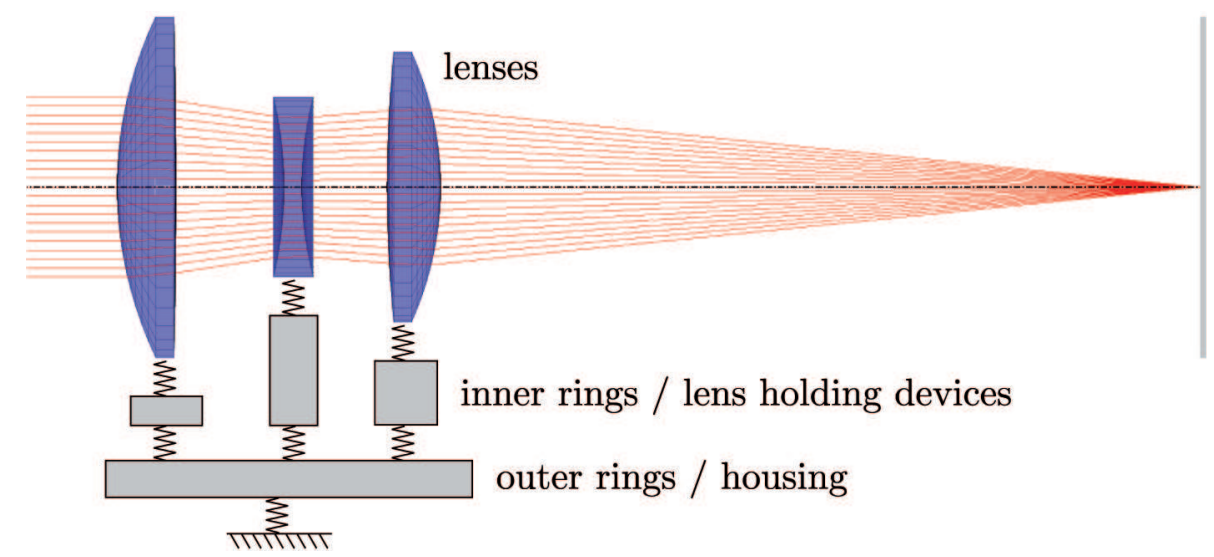

Fig. 1. The mechanical model of a lens triplet

The motion of a single lens is described by the movement $\rho$ of the center of the first surface and by the orientation as displayed in Fig. 2. The orientation depends on two rotations, $\theta_{x}$ and $\theta_{y}$. A rotation about the third axis, the axis of rotational symmetry, can be neglected since this would not 
affect the optical simulation. So each lens of the $k$ lenses has five degrees of freedom. All lens movements are summarized in the vector

$$
\boldsymbol{y}=\left[\rho_{x, 1}, \rho_{y, 1}, \rho_{z, 1}, \theta_{x, 1}, \theta_{y, 1}, \ldots \rho_{x, k}, \rho_{y, k}, \rho_{z, k}, \theta_{x, k}, \theta_{y, k}\right]^{T} .
$$

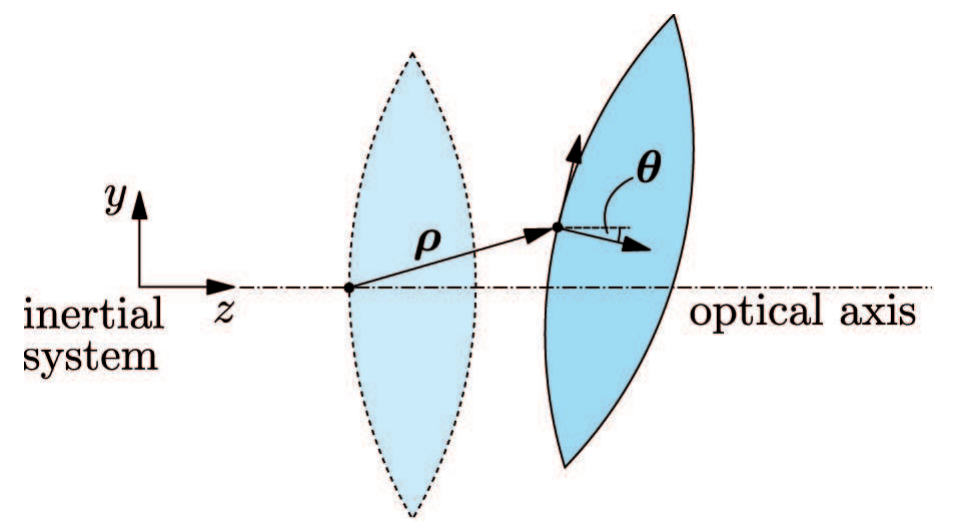

Fig. 2. Kinematical description of a single lens

Only small vibrations are of interest, and nonlinear motion effects do not occur in those systems. Therefore, the equations of motion are linear by their physics. They have the form

$$
\begin{aligned}
\boldsymbol{M} \cdot \ddot{\boldsymbol{q}}(t)+\boldsymbol{D} \cdot \dot{\boldsymbol{q}}(t)+\boldsymbol{K} \cdot \boldsymbol{q}(t) & =\boldsymbol{B} \cdot \boldsymbol{u}(t) \\
\boldsymbol{y}(t) & =\boldsymbol{C} \cdot \boldsymbol{q}(t)
\end{aligned}
$$

with the generalized coordinates $\boldsymbol{q}$, the mass matrix $\boldsymbol{M}$, the damping matrix $\boldsymbol{D}$, the stiffness matrix $\boldsymbol{K}$, the input matrix $\boldsymbol{B}$, the inputs $\boldsymbol{u}$ and the output matrix $\boldsymbol{C}$. The lens movements observed in the output $\boldsymbol{y}$ can be passed directly to a raytracing simulation.

\subsection{Chief ray deviation and wavefront aberration}

The imaging quality of an optical system can be determined by different descriptions of aberrations [5]. In the special case of investigating the motion of lenses, a promising method is to distinguish between chief ray deviation (CRD) $\boldsymbol{a}_{c r d}$ and wavefront aberration (WFA) $\boldsymbol{a}_{w f a}$, see Fig. 3. In the lower left figure, a mixture of the two aberrations of the upper figures can be seen. The figure without any disturbance serves as contrast to the aberration drafts. It shows an ideal imaging as well as the object plane and image plane. The light always directs from the object to the image.

In geometrical optics, it is common to use point light sources which are the starting point of a ray bundle, the so-called fields. The ray that crosses 

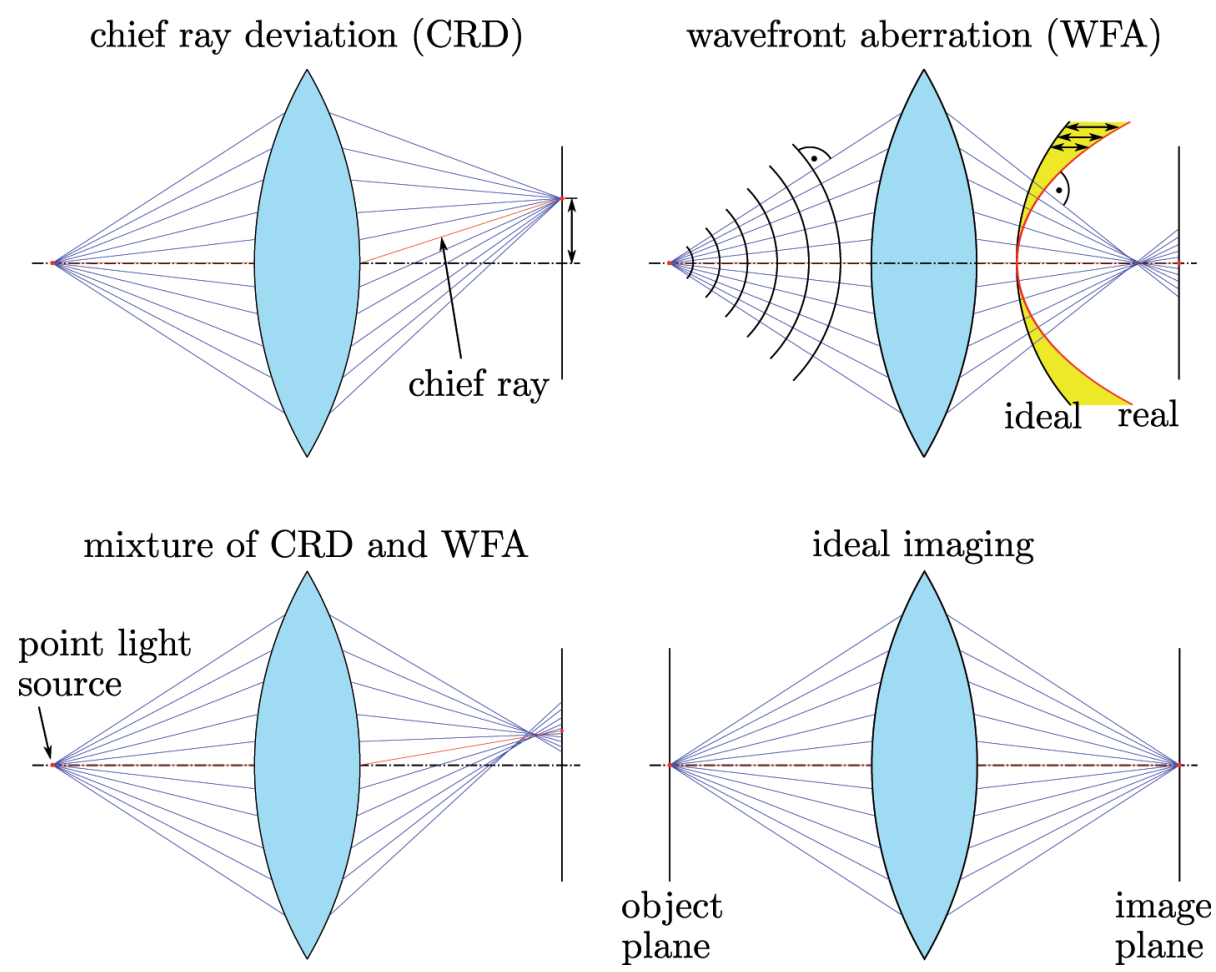

Fig. 3. Scheme of chief ray deviation and wavefront aberration

the optical axis at the system aperture is called the chief ray. This is usually the center ray of a ray bundle. If some lenses are perturbed, the chief ray gets deviated at the image plane, which will be described by $x_{c r d}$ and $y_{c r d}$. Several fields are required to described an object, so the deviations of the several chief rays determine the movement and distortion of an image. The chief ray deviation does not occur in perfectly mounted static systems.

In theory, the point light sources produce spherical waves. The wavefronts are perpendicular to the rays. In an ideal case, the wavefronts are still spherical after they passed an optical system, i.e. all rays hit the image plane at one point. If the rays hit the image plane somehow scattered, the wavefront is deformed. The wavefront aberration is the difference between an ideal wavefront and a deformed wavefront. It is a measure for the blurring of an image and it can be quantified by an expansion in Zernike polynomials. Another quantification is possible be computing the root mean square (RMS). 


\subsection{Zernike polynomials}

Zernike polynomials $Z_{j}$ are orthogonal polynomials with a unit circle base, see $[5,6]$. They consist of a radial-dependent part

$$
R_{n}^{m}=\sum_{k=0}^{(n-m) / 2} \frac{(-1)^{k}(n-k) !}{k !((n+m) / 2-k) !((n-m) / 2-k) !} r^{n-2 k}
$$

with the normalized radius $r$ and an angular-dependent part with the angle $\phi$. The indices $m$ and $n$ are positive integers with $n \geq m$. There exist different notations for the polynomials. Here, the standard notation introduced in [7] is used due to its advantages in computer programming. The Zernike standard polynomials $Z_{j}$ read

$$
\begin{array}{ll}
Z_{j}(r, \phi)=\sqrt{2(n+1)} R_{n}^{m}(r) \cos (m \phi), & \text { if } m \neq 0 \text { and } j \text { even, } \\
Z_{j}(r, \phi)=\sqrt{2(n+1)} R_{n}^{m}(r) \sin (m \phi), & \text { if } m \neq 0 \text { and } j \text { odd, } \\
Z_{j}(r)=\sqrt{n+1} R_{n}^{m}(r), & \text { if } m=0 .
\end{array}
$$

The expansion of $\boldsymbol{a}_{w f a}$ in $\bar{k}$ Zernike polynomials $Z_{j}$ means describing the wavefront aberration by $\bar{k}$ Zernike coefficients $c_{j}$,

$$
\boldsymbol{a}_{w f a}=\left[c_{1}, c_{2}, \ldots c_{\bar{k}}\right]^{T} .
$$

This corresponds to a subdivision into characteristic aberrations which are, e.g., defocus $\left(Z_{4}\right)$, spherical aberration $\left(Z_{11}\right)$, coma, etc. The coefficients $c_{j}$ are used to describe the wavefront aberration and, therefore, the blurring of the projected image. The wavefront aberration is a circular area $\zeta$ defined by discrete points and it is scaled to the unit circle. Generally, the wavefront aberration evaluated by Zernike polynomials reads

$$
\zeta=\sum c_{j} Z_{j}
$$

In index notation, each discrete point $\zeta_{i}\left(r_{i}, \theta_{i}\right)$ of the wavefront aberration is defined by $Z_{j, i}\left(r_{i}, \theta_{i}\right)$,

$$
\zeta_{i}=\left[Z_{1, i}, Z_{2, i}, \ldots Z_{\bar{k}, i}\right] \cdot \boldsymbol{a}_{w f a}
$$

where the coefficients in $\boldsymbol{a}_{w f a}$ are unknown. The equation system derived for all discrete points is usually overdetermined and has to be solved by a least-squares algorithm. 


\subsection{Dynamical-optical sensitivities}

In the case of small movements, the aberrations $\boldsymbol{a}_{c r d}$ and $\boldsymbol{a}_{w f a}$ are proportional to the lens movements $\boldsymbol{y}$ of Eq. (3). This can be expressed by the dynamical-optical sensitivities $\boldsymbol{S}$,

$$
\boldsymbol{a}=\left[\begin{array}{c}
\boldsymbol{a}_{c r d} \\
\boldsymbol{a}_{w f a}
\end{array}\right]=\boldsymbol{S} \cdot \boldsymbol{y}
$$

with the sensitivities $\boldsymbol{S}=\left[\boldsymbol{S}_{1}, \boldsymbol{S}_{2}, \ldots \boldsymbol{S}_{k}\right]$ for $k$ lenses and, considering a single field, for one lens $i$

$$
\boldsymbol{S}_{i}=\left[\begin{array}{c|c|c|c|c}
x_{c r d, x} & x_{c r d, y} & x_{c r d, z} & x_{c r d, \theta_{x}} & x_{c r d, \theta_{y}} \\
y_{c r d, x} & y_{c r d, y} & y_{c r d, z} & y_{c r d, \theta_{x}} & y_{c r d, \theta_{y}} \\
c_{1, x} & c_{1, y} & c_{1, z} & c_{1, \theta_{x}} & c_{1, \theta_{y}} \\
\vdots & \vdots & \vdots & \vdots & \vdots \\
c_{\bar{k}, x} & c_{\bar{k}, y} & c_{\bar{k}, z} & c_{\bar{k}, \theta_{x}} & c_{\bar{k}, \theta_{y}}
\end{array}\right] .
$$

Each column represents the aberrations of a unity movement in one degree of freedom. Then, inserting Eq. (3) in Eq. (9) leads to

$$
a=\underbrace{S \cdot C}_{C_{s}} \cdot q .
$$

The sensitivities in $S$ are strictly related to the design of the optical system. When investigating a certain optical design, $\boldsymbol{S}$ has to be calculated only once. For each column in $\boldsymbol{S}$, one raytracing simulation is required. Once $\boldsymbol{S}$ is known, using Eq. (11) is advantageous for simulations in the time domain. The other possibility would be calculating the aberrations at each time step which is, in general, less efficient.

\subsection{A formalism including modal transformation}

The previously discussed sensitivities will now be expanded to a method which is essential for the optimization process. This method allows for a direct evaluation of the dynamical design quality of an optomechanical system. Therefore, the main idea of this method will be used in Section 3.1. to define the objective function of the optimization.

The characteristics of a dynamical system described by Eq. (2) can be investigated by means of the eigenvalue problem

$$
\left(\boldsymbol{K}-\omega_{j}^{2} \boldsymbol{M}\right) \cdot \phi_{j}=\mathbf{0}
$$


with the $j$-th eigenfrequency $\omega_{j}$ and the associated mode shape $\phi_{j}$. When a vibrating system is freezed at an arbitrary point in time $t^{*}$, the state of the system is a superposition of the mode shapes,

$$
\boldsymbol{q}\left(t^{*}\right)=\sum_{j=1}^{n} d_{j}\left(t^{*}\right) \phi_{j}
$$

with $d_{j}$ being the amplitudes of the corresponding mode shapes and $n$ being the number of degrees of freedom. The $n$ mode shapes can be summarized in

$$
\boldsymbol{\Phi}=\left[\phi_{1}, \phi_{2}, \ldots \phi_{n}\right]
$$

For the following calculations, the mode shapes $\boldsymbol{\Phi}$ will be used to scale the mass matrix

$$
\boldsymbol{\Phi}^{T} \cdot \boldsymbol{M} \cdot \boldsymbol{\Phi}=\boldsymbol{I}
$$

where $\boldsymbol{I}$ is the identity matrix. Using the substitution $\boldsymbol{q}=\boldsymbol{\Phi} \cdot \tilde{\boldsymbol{q}}$ with the modal coordinates $\tilde{\boldsymbol{q}}$ and premultiplying Eqs. (2) and (3) by $\boldsymbol{\Phi}^{T}$ leads to the modally transformed equations of motion,

$$
\begin{aligned}
\boldsymbol{\Phi}^{T} \cdot \boldsymbol{M} \cdot \boldsymbol{\Phi} \cdot \ddot{\tilde{\boldsymbol{q}}}+\boldsymbol{\Phi}^{T} \cdot \boldsymbol{D} \cdot \boldsymbol{\Phi} \cdot \dot{\tilde{\boldsymbol{q}}}+\boldsymbol{\Phi}^{T} \cdot \boldsymbol{K} \cdot \boldsymbol{\Phi} \cdot \tilde{\boldsymbol{q}} & =\boldsymbol{\Phi}^{T} \cdot \boldsymbol{B} \cdot \boldsymbol{u} \\
\boldsymbol{y} & =\boldsymbol{C} \cdot \boldsymbol{\Phi} \cdot \tilde{\boldsymbol{q}}
\end{aligned}
$$

The modal coordinates $\tilde{\boldsymbol{q}}$ are equal to the amplitudes $d_{j}$ in Eq. (13). Using the scaling of Eq. (15), Eq. (16) becomes

$$
\ddot{\tilde{\boldsymbol{q}}}+\operatorname{diag}\left(2 \omega_{i} \xi_{i}\right) \cdot \dot{\tilde{\boldsymbol{q}}}+\operatorname{diag}\left(\omega_{i}^{2}\right) \cdot \tilde{\boldsymbol{q}}=\tilde{\boldsymbol{B}} \cdot \boldsymbol{u}
$$

Inserting Eq. (17) in Eq. (9) yields

$$
\boldsymbol{a}=\underbrace{\boldsymbol{S} \cdot \boldsymbol{C} \cdot \boldsymbol{\Phi}}_{\tilde{\boldsymbol{C}}_{s}} \cdot \tilde{\boldsymbol{q}}
$$

The matrix $\tilde{\boldsymbol{C}}_{s}$ indicates the aberrations of a mode shape. This matrix can either be calculated like in Eq. (19), or can be computed by applying the lens movements of the mode shapes to the optical system and doing a raytracing simulation. Using Eq. (19), we now can compute the optical aberrations $\boldsymbol{a}$ from the modally described lens movements $\tilde{\boldsymbol{q}}$. 


\section{Optimization of the mode shapes}

Usually, the mechanical design for an optical system is customized with respect to the optical design. So it is the idea of this method to improve an existing mechanical design without touching the optical design. Here, improving the design means systematically adjusting mode shapes which produce small aberrations. The improved dynamical behavior can be found by means of numerical optimization methods where the masses and stiffnesses are adjusted.

\subsection{The performance function}

In dynamical systems, knowing the input/output behavior is essential. Here, the input is an excitation and the outputs are the aberrations $\boldsymbol{a}$. The behavior is described by a dynamical-optical transfer function $\boldsymbol{H}(i \omega)$ derived from the modally transformed system in Eqns. (18) and (19)

$$
\|\boldsymbol{H}(i \omega)\|=\sum_{j=1}^{n} \frac{\left\|\left[\tilde{\boldsymbol{C}}_{s}\right]_{* j}[\tilde{\boldsymbol{B}}]_{j *}\right\|}{-\omega^{2}+\omega_{j}^{2}+2 i \omega \omega_{j} \xi_{j}} .
$$

The product $\left[\tilde{\boldsymbol{C}}_{s}\right]_{* j}[\tilde{\boldsymbol{B}}]_{j *}$ is the dyadic product of the $j$-th column of $\tilde{\boldsymbol{C}}_{s}$ and the $j$-th row of $\tilde{\boldsymbol{B}}$. Following from Eqn. (20), the substitution

$$
w_{\text {optical }, j}=\frac{\left\|\left[\tilde{\boldsymbol{C}}_{s}\right]_{* j}[\tilde{\boldsymbol{B}}]_{j *}\right\|}{\omega_{j}}
$$

determines the influence of an unitary sinusoidal excitation on the aberration of a mode shape. Using $w_{\text {optical }, j}$ as weighting factor, the optimization problem

$$
\begin{aligned}
& \min f(\boldsymbol{p}) \quad \text { with } \quad f(\boldsymbol{p})=\sum_{j=1}^{k}\left|\tilde{\boldsymbol{C}}_{s} \cdot w_{\text {optical }, j} \phi_{j}\right| \\
& \text { subject to } \quad \boldsymbol{p}_{\min } \leq \boldsymbol{p} \leq \boldsymbol{p}_{\max }
\end{aligned}
$$

is specified by the sum of the weighted aberrations of $k$ selected mode shapes.

Before or during the optimization, mode shapes have to be selected. For this, the user has two possibilities. On the one hand, he can in advance select mode shapes by their number. On the other hand, he can chose a frequency range. All mode shapes corresponding to an eigenfrequency within this range will then be selected during the evaluation of the performance function. 
It is additionally possible to 'weight' the mode shapes by their eigenfrequencies. For this, the function $w_{\text {excitation }}(\omega)$ has to be defined, which represents the frequency spectrum of the excitation of the simulation model. This frequency spectrum is known or should at least be guessed from experience. The quality of the optimization results increases with the accuracy of the frequency spectrum estimation. Multiplying $w_{\text {excitation }}\left(\omega_{j}\right)$ with $w_{\text {optical }, j}$ leads to a new weighting factor $w_{j}$ which replaces $w_{o p t i c a l}, j$ in the performance function,

$$
f(\boldsymbol{p})=\sum_{j=1}^{k}\left|\tilde{\boldsymbol{C}}_{s} \cdot w_{j} \phi_{j}\right|
$$

\subsection{Software implementation of the optimization}

The software implementation of the computation of the performance function contains the generation of the mass and stiffness matrix, solving the eigenvalue problem, scaling the eigenvectors and computing the performance function $f(\boldsymbol{p})$ using Eqn. (23). A basic scheme is shown in Fig. 4.

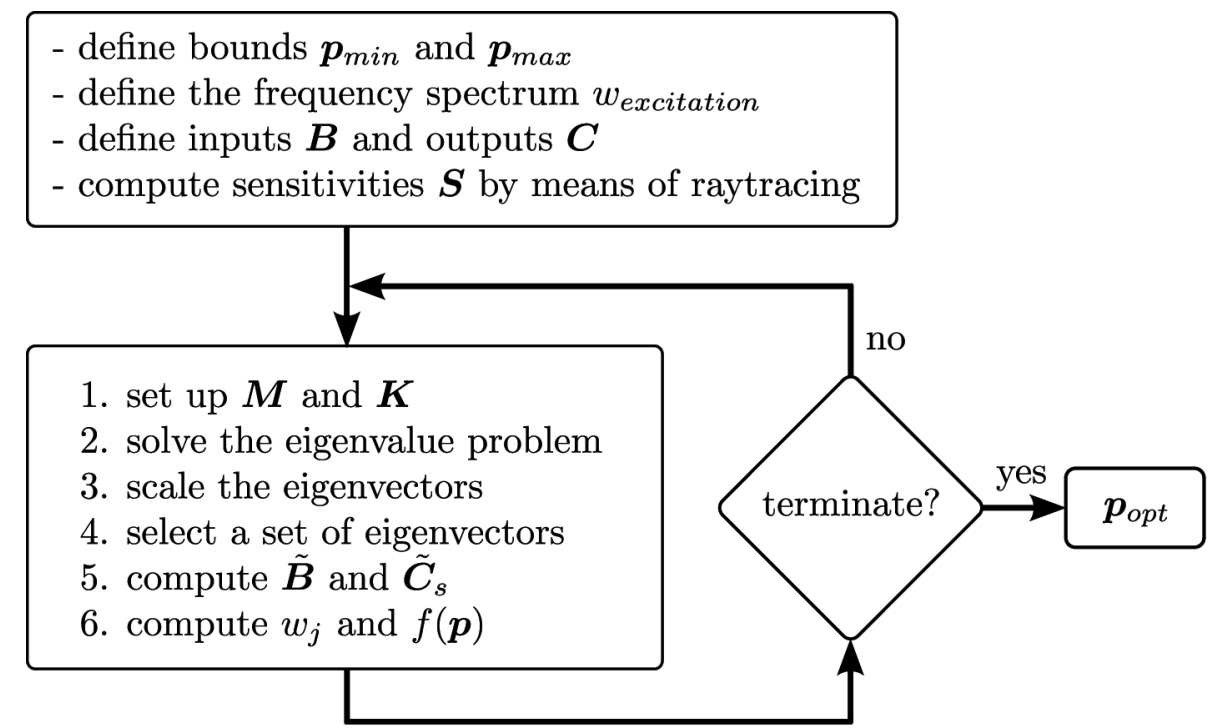

Fig. 4. The optimization process

A disadvantage of the method shown is the requirement of a solution of the eigenvalue problem in each iteration step. Increasing the performance is possible by calculating only a fixed number of smallest eigenvalues.

Sometimes in optimizing dynamical systems, the transfer function for a frequency range is summed up in each iteration step in order to calculate 
the performance function. However, if damping is neglected, this leads to inaccuracies due to the peaks at the eigenfrequencies. Furthermore, a matrix inversion is required for computing the transfer function.

The performance function has usually many local minima, thus a stochastic optimization algorithm is required to ensure good solutions. Here, a Particle Swarm Optimization (PSO) algorithm named ALSPO [8] is used which is written in Matlab and treats constraints using an Augmented Lagrangian Optimization technique. For general information about PSO see $[9,10]$.

The results are compared to a deterministic algorithm for which the Sequential Quadratic Programming (SQP) method is chosen. In general, the NLPQL algorithm [11] in the Matlab implementation fmincon() yields good results and, therefore, will be applied here.

Optimization algorithms usually require a scaling of the design parameters,

$$
\bar{p}_{i}=\left(\bar{p}_{\text {max }}-\bar{p}_{\text {min }}\right) \frac{p_{i}-p_{\text {min }, i}}{p_{\text {max }, i}-p_{\text {min }, i}}-\bar{p}_{\text {min }} \quad \text { with } \quad \bar{p}_{\text {min }} \leq \overline{\boldsymbol{p}} \leq \bar{p}_{\text {max }} .
$$

In the following computations, $\bar{p}_{\min }=-10$ and $\bar{p}_{\max }=10$ are used.

\section{Optimization of a lithography objective}

The introduced methods will now be applied to a lithography objective from [12]. The cross section of the lenses and the ray bundles of two point light sources are presented in Fig. 5.

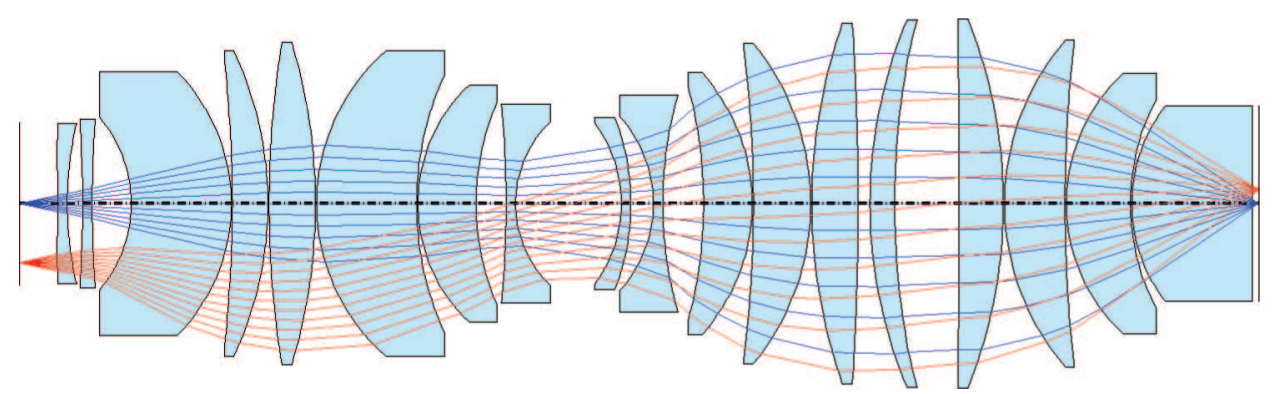

Fig. 5. Optical design of a lithography objective with an on-axis field and an off-axis field

In this optimization process, a mechanical model is used. It is similar to the lens triplet in Fig. 1, but consists of more lenses. The design parameters $\boldsymbol{p}$ contains 56 parameters in total which are the mass of the housing $m_{H}$, the masses of the inner rings $m_{I R}$, the spring coefficients of the connections between frame and housing $k_{F H}$, between housing and inner rings $k_{H I}$ and between inner rings and lenses $k_{I L}$,

$$
\boldsymbol{p}=\left[m_{H}, m_{I R, 1}, \ldots k_{F H}, k_{H I, 1}, \ldots k_{I L, 1}, \ldots\right] .
$$


The optimization process comprises the optimization of transversal motion. The motion is only represented by movements in $y$-direction and the $x$-direction is left out since the lens system is assumed to be rotationally symmetric about the $z$-axis. Unfortunately, either chief ray deviation or wavefront aberration can be minimized. Minimizing both simultaneously would require a multi-objective optimization, so here, only the chief ray deviation is concerned in the performance function.

To give an overview about several sets of design parameters, four different results/ choices will be presented. Regarding industrial applications, it is typical to improve existing designs. So the first design is the initial guess $\boldsymbol{p}_{\text {initial }}$ which is meant to represent an existing but not yet mathematically optimized guess. Then, there are two optimized designs, an SQP-optimized $\boldsymbol{p}_{\text {opt,sqp }}$ for the deterministic solution and the PSO-optimized $\boldsymbol{p}_{\text {opt,pso }}$. To compare them all to a poor design, $\boldsymbol{p}_{\text {maxerror }}$ with a maximum aberration is calculated by maximizing the chief ray deviation with the ALPSO algorithm. This gives an idea about how a bad design might look like.

\subsection{Excitation model for time simulations}

To validate the optimization results, simulations in the time domain with subsequent image simulations are performed. For the time simulations, an excitation is required, which is applied at the housing of the objective, see Fig. 6. Once the lens movements are calculated, the aberrations can be computed and can be visualized by means of geometric image simulations.

As stated in Section 3.2, practically meaningful optimization results will be obtained if an additional weighting of the mode shapes matches the frequency spectrum of the excitation. In the following example, the force excitation in Fig. 6 will be used for validations in the time domain. This force corresponds to a shock of a soft hammer. Thus, the system is able to perform free vibrations after a short excitation. The curve of the Fourier transform serves as the additional weighting function $w_{\text {excitation }}$ within the performance function to weight the aberrations of the selected mode shapes.

\subsection{Optimization results}

The transfer behaviors in Fig. 7 show the results of optimizing the transversal motion. The four models are subjected to an input at the housing, and the chief ray deviation of the on-axis field serves as criterion of the optimization. The curves of the optimized models are significantly lower than those of the other two designs. Accordingly, the aberrations will be lower. It can be stated that the optimizations succeeded and the method works in the frequency domain. The values of the performance func- 

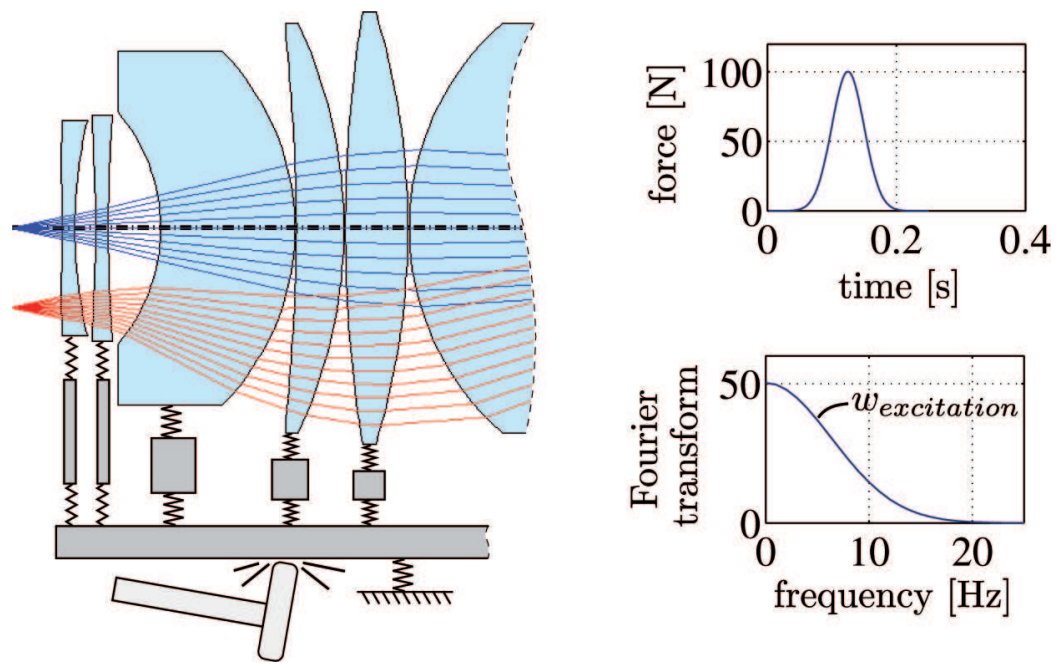

Fig. 6. Mechanical model with the hammer shock excitation (left), time history of the shock of a soft hammer and its Fourier transform (right)

tions are $f\left(\boldsymbol{p}_{\text {initial }}\right)=11.852, f\left(\boldsymbol{p}_{\text {maxerror }}\right)=25.923, f\left(\boldsymbol{p}_{\text {opt sqp }}\right)=0.393$ and $f\left(\boldsymbol{p}_{\text {opt }, p s o}\right)=0.065$.

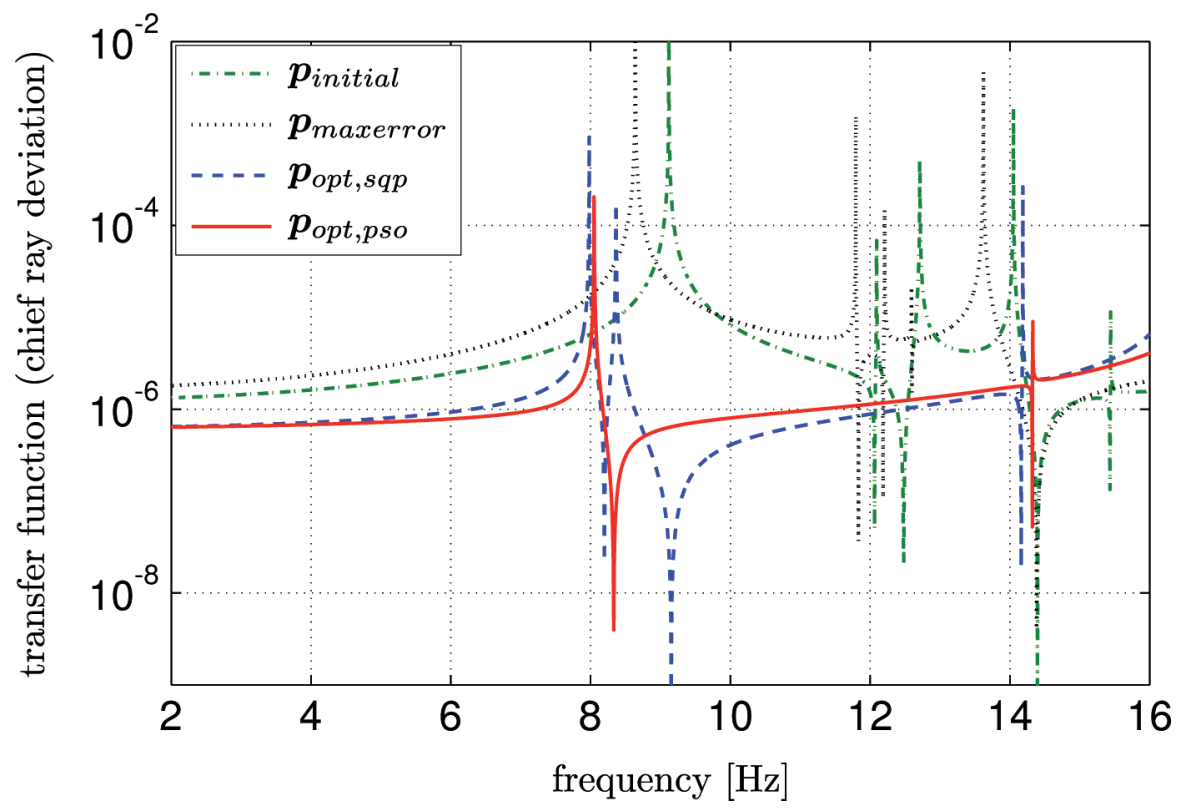

Fig. 7. Transfer functions of the four dynamical-optical models

For the validation in the time domain, Fig. 8 represents the results for the two optimized designs. Here, the difference between $\boldsymbol{p}_{\text {opt,sqp }}$ and $\boldsymbol{p}_{\text {opt,pso }}$ is even more obvious than in Fig. 7. Additionally, the RMS of the wavefront 
aberration is given although only the chief ray deviation has been optimized. At the beginning of the simulation, there is a peak in all curves which results from the hammer shock. Furthermore, $\boldsymbol{p}_{\text {optsqp }}$ exhibits beats in both the chief ray deviation and the wavefront aberration in phase. The beats do not occur for the PSO-optimized parameters which makes them better than the SQPoptimized parameters.

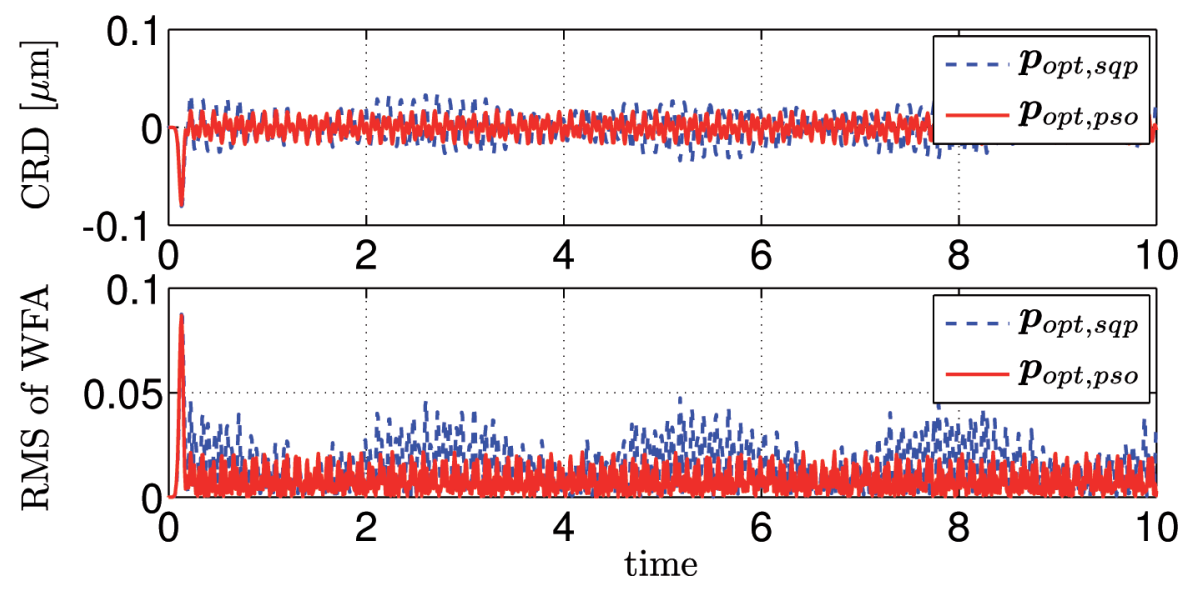

Fig. 8. Chief ray deviation and wavefront aberration after a hammer shock on the housing of the two optimized models

A comparison in the time domain of all four models is summarized in Fig. 9. With the time range of 0 to 10 seconds, as in Fig. 8, the RMS values of the aberration curves are computed. For both aberration types the ratios of the reduction are approximately equal and they correspond to the ratios of the performance function results. However, the wavefront aberration is not included in the performance function and thus, its minimization is a side effect of the optimization. As the diagrams show, the PSO method yields the lowest aberrations in both cases.

\subsection{Geometric image simulations}

A geometric image simulation comprises a raytracing simulation with a test object where millions of rays start with random direction from random point light sources. The image screen is subdivided into pixels. At each pixel, the hitting rays are counted which yields an intensity distribution of a projected image. Integrating the intensity distribution over a time range yields a map for the energy distribution of an exposure.

The exposure of the letter ' $F$ ' is demonstrated in Fig. 10. In this example, the same parameter sets and excitation as in the previous section are used. The time range of the exposure is 2.0 to 2.3 seconds. Expectedly, the images of 

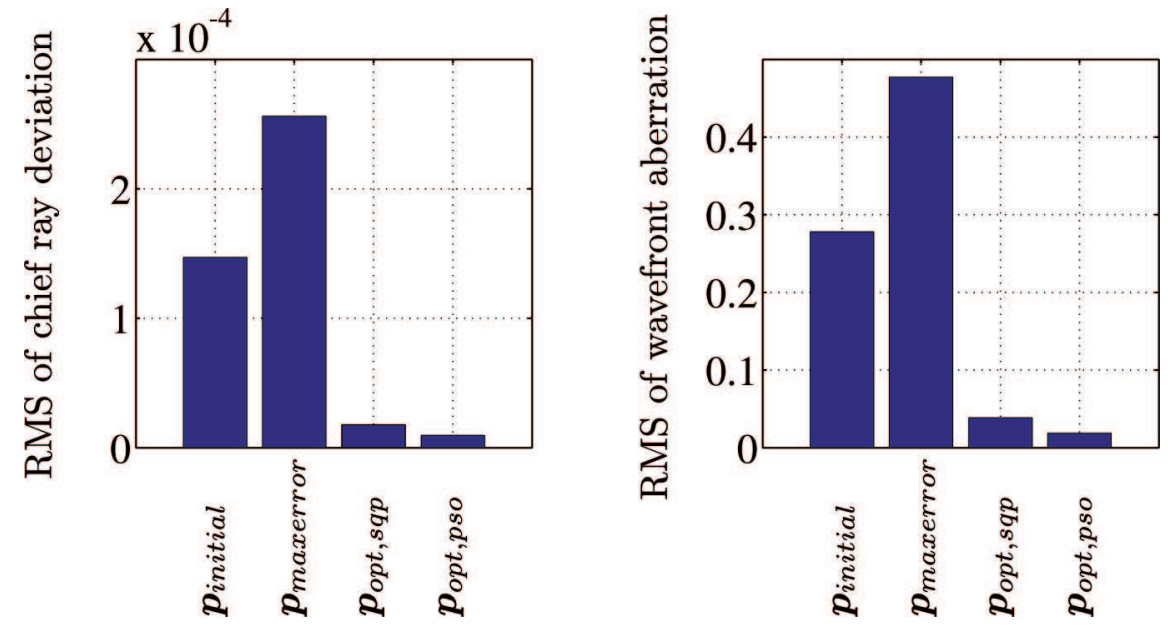

Fig. 9. RMS of the chief ray deviation curve and the wavefront aberration curve after a hammer shock in $y$-direction

the non-optimized models are more blurred due to large vertical movements. These movements are much smaller for the images of the optimized models. Thus, the image quality is improved significantly. The blurring at the vertical edges is mainly due to the system-inherent aberrations.

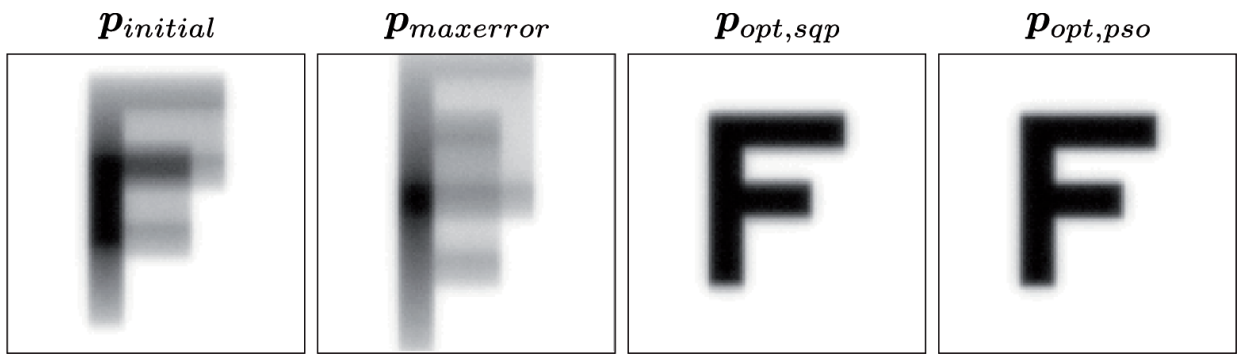

Fig. 10. Image simulations over a time range for pointing out the effect of the hammer shock on a projected image

\section{Conclusions and Outlook}

For optomechanical systems which can be modeled by rigid bodies the optimization method in this paper can improve an existing design. The optimization works most notably if it is applied to the expected frequency spectrum of possible excitations.

Based on these methods, some expansions are possible to gain even better results. For example, including an adaptation of the optical design within the performance function. This has to be implemented by an additional opti- 
cal optimization regarding the dimensions of the lenses. Also, the influence of lens deformations has to be taken into account. This is due to possible changes in the stiffness of the supports of the lenses which influences the deformation behavior.

\section{Acknowledgements}

The authors would like to thank the German Research Foundation (DFG) for financial support of the project within the Cluster of Excellence in Simulation Technology (EXC 310/1, SimTech) at the University of Stuttgart. Special thanks go to useful discussions and advice from the Institute of Applied Optics (ITO), Holger Gilbergs, Karsten Frenner and Wolfgang Osten. All this support is highly appreciated.

Manuscript received by Editorial Board, September 23, 2011; final version, November 11, 2011.

\section{REFERENCES}

[1] Mack C.: Fundamental Principles of Optical Lithography. Chichester: John Wiley and Sons, 2007.

[2] Schriever M., Wegmann U., Hembacher S., Geuppert B., Huber J., Kerwien N., Totzeck M., Hauf M.: Optical Apparatus and Method for Modifying the Image Behavior of such Apparatus. Patent US 2009/0174876, 2009.

[3] Shibazaki Y.: Optical Element Holding Apparatus. Patent US 2007/0121224, 2007.

[4] Schiehlen W., Eberhard P.: Technische Dynamik - Modelle für Regelung und Simulation (in German). Wiesbaden: Teubner, 2004.

[5] Born M., Wolf E.: Principles of Optics. Cambridge: University Press, 1999.

[6] Zernike F.: Beugungstheorie des Schneidenverfahrens und seiner verbesserten Form, der Phasenkontrastmethode (in German). Physica 1, pp. 689-704, 1934.

[7] Noll R.: Zernike Polynomials and Atmospheric Turbulence. Journal of the Optical Society in America, Vol. 66, No. 3, pp. 207-211, 1976.

[8] Sedlaczek K., Eberhard P.: Using Augmented Lagrangian Particle Swarm Optimization for Unconstrained Problems in Engineering. Structural and Multidiscipinary Optimization, Vol. 32, No. 4, pp. 277-286, 2006.

[9] Sedlaczek K., Eberhard P.: Augmented Lagrangian Particle Swarm Optimization in Mechanism Design. Journal of System Design and Dynamics, Vol. 1, pp. 410-421, 2007.

[10] Kennedy J., Eberhart R.: Swarm Intelligence. San Diego: Academic Press, 2001.

[11] Schittkowski K.: NLPQL: A Fortran Subroutine Solving Constrained Nonlinear Programming Problems. Annals of Operations Research, Vol. 5, pp. 485-500, 1985.

[12] Ulrich W., Rostalski H.J.: Projection Objective for Immersion Lithography. Patent US 2010/0323299, 2010. 


\section{Optymalizacja właściwości dynamicznych systemów obiektywów o wysokiej dokładności w celu redukcji aberracji dynamicznych}

\section{Streszczenie}

W systemach obiektywów wysokiej klasy nawet małe zakłócenia mogą spowodować nieostrość projekcji obrazu. Ogromny problem dla tych niezwykle precyzyjnych systemów optyczno-mechanicznych stanowią na przykład niewielkie pobudzenia o charakterze stochastycznym. Jest do pomyślenia szereg środków, by uniknąć związanych z tym problemów, a przynajmniej by je ograniczyć. Jedną z takich możliwości jest modyfikacja właściwości dynamicznych. W metodzie tej, w celu zmniejszenia aberracji powodowanych przez pobudzenia dynamiczne, stosuje się redystrybucję mas i sztywności systemu.

Wymagany w tym przypadku jest multidyscyplinarny proces optymalizacyjny, dla potrzeb którego w artykule wprowadza się podstawy połączonych dynamicznych i optycznych metod stymulacji. Optymalizacja jest oparta na metodzie zapewniającej efektywne połączenie tych dwu typów stymulacji. W końcowym przykładzie przedstawiono optymalizację dynamiki ciała sztywnego reprezentującego obiektyw litograficzny pod kątem jego właściwości dynamiczno-optycznych. 